\title{
THE 6th AFIR INTERNATIONAL COLLOQUIUM
}

Nürnberg, Germany, 1996

The 6th AFIR International Colloquium was held at the Hotel Maritim in Nürnberg, Germany from 1 to 3 October, 1996 with about 190 participants from 17 different countries. Although most participants were from European countries there were a significant number from other countries including Australia, Israel, Japan, Taiwan, and USA. The organisation of the Colloquium was superb and the quality of the presented papers very high. There were almost 70 contributed papers. The Scientific Committee, chaired by Peter Albrecht, and the Organization Committee, chaired by Peter Burghard, are to be congratulated for an excellent meeting. Invited lectures in Plenary sessions began both the morning and afternoon program. Parallel sessions were then used to allow the authors of the contributed papers a reasonable time to present the main ideas in their papers. This meeting format worked well allowing participants to attend sessions in their area of interest.

The social program for accompanying persons included bus tours to Bamberg, Rothenberg, a walk through "Romantic Nürnberg" and a guided tour of the court room of the "Nürnberg Trials". All of this looked enticing but most of us were there for the business side of the meeting.

On completion of the Opening formalities on Tuesday 1 October the first invited lecture was by Hans Foellmer from Humboldt-University of Berlin on "Recent Developments in Option Pricing Theory". Option Pricing has been a theme of past AFIR Colloquia and this presentation was most appropriate. It covered developments in stochastic mathematics and issues of incomplete markets. There followed parallel sessions with contributed papers on Option Pricing and on Asset Liability Management. The area of asset-liability management has also been a common theme of previous colloquia.

After lunch, which provided the opportunity for further discussion and networking, the invited lecture was by Paul Embrechts of ETH Zurich with an advertised topic of "Methodological Issues Underlying Value at Risk Estimation". Paul's lecture emphasised modelling extreme values and the use of the generalised extreme value distributions including the Wiebul, Fréchet (Pareto related) and Gumbel (double exponential) cases. Moreover, the generalised Pareto distributions are useful models for excess distributions. He mentioned that software for extreme value modelling was available from the World-Wide-Web site http://www.math.ethz.ch/ $\sim$ moneil/software.html and Paul also referred to a forthcoming book by Embrechts, Kluppelberg and Mikosh on "Modelling Extremal Events for Insurance and Finance" to be published by Springer in 1997.

One of the afternoon parallel sessions was on the topic of Risk Measurement and Risk Control and the other was on Asset-Liability Management. The Risk Measurement and Risk Control papers covered the areas of Value at Risk, Derivatives and reporting and supervision. The asset-liability session covered papers 
on pension fund and life insurance asset liability modelling and asset allocation including optimal asset allocation strategies. In the evening the participants and accompanying persons adjourned to the Germanisches Nationalmuseum for a performance of the opera "The Abduction from the Seraglio" by Wolfgang Amadeus Mozart followed by a stand up reception. This excellent performance was especially presented for the AFIR Colloquium and the evening was most enjoyable.

Wednesday 2 October commenced with an invited lecture by Wolfgang Buehler from the University of Mannheim on "An Empirical Comparison of Valuation Models for Interest Rate Derivatives". The area of term structure models and their use in finance and actuarial applications has been an area of rapid theoretical development and understanding the different models and when they are most appropriate is an important topic. I am sure there will be more contributions to this area as actuaries increase their use of term structure models.

The two parallel sessions following included one on Applications of Options in Investment Management and Insurance and one on Bond Valuation and Bond Management. The options session covered a wide range of topics including shortfall risks and the pricing of the new forms of guaranteed index-linked life insurance policies. These policies have been recently introduced in Germany and are also popular now in North America. They demonstrate the potential of exotic options for product design in life insurance and will be an area of much future interest as these products become more popular internationally. The bond valuation session looked interesting but I chose to attend the options session.

The afternoon of Wednesday was free and participants had the choice of a tour of the city or a special guided tour of the Germanisches Nationalmuseum. In the evening the social activities were "Frolics at the Imperial Castle". Europe is rich in history and, as these events testified, Nürnberg is no exception.

The final day of the Colloquium was a holiday in Germany (German Unity Day). It opened with an invited lecture by David Wilkie on The European Single Currency. For both European and overseas participants this was a most interesting lecture. The intricacies involved in moving to a common currency range from deciding on a name for the currency to adjusting computer programs. The following parallel sessions covered Applications of Numerical and Econometrical Methods in Finance and Portfolio-Capital Market Theory and Investment Management. The Numerical and Econometric presentations included topics on Neural Networks, Genetic algorithms, and error correction models.

The final invited lecture was by Gerhard Rupprecht of Allianz Lebensversicherungs-AG who spoke on "The European Monetary Union from the Perspective of a German Life Insurer" providing another perspective on this topic to that given by David Wilkie in the morning lecture. The following parallel sessions were on Current Problems in Insurance and Finance and covered a wide range of interesting topics. 
The scientific program finished with a closing session summing up the Colloquium and with Catherine Prime from Australia inviting everyone to the 7th International AFIR Colloquium to be held in Cairns Australia from 13-15 August 1997 with a joint day with the ASTIN Colloquium on 13 August. We are all looking forward to next year and we have been inspired by the organisation of the Nürnberg Colloquium and intend adopting a similar structure with invited lectures and parallel sessions. Already arrangements are well in hand and those who wish to submit a paper should notify the Chair of the Scientific Committee (Mike Sherris) by email (msherris@efs.mq.edu.au) or by Fax (+6129850 8572) as soon as possible. Final papers are due by 1 March 1997. The call for papers can be viewed at http://www.ocs.mq.edu.au/ msherris/afir97.html which includes instructions for authors.

For those who did not attend the Colloquium I can recommend that you obtain the Proceedings. There were many topics covered and you will no doubt find some new ideas.

The Colloquium concluded with a Gala night at the Hotel Maritim with entertainment, fine food and, most of all, fine company.

MiKe SHERRIS

School of Economic and Financial Studies

Macquarie University

Sydney NSW

Australia 2109 